\title{
Peer Community In, a free and transparent initiative for preprint peer-reviewing. We did it in Archaeology, why not in Geochemistry?
}

ALAIN QUEFFELEC ${ }^{1}$, BRUNO MAUREILLE ${ }^{2}$ AND SÉBASTIEN VILLOTTE ${ }^{3}$

${ }^{1}$ INRAE 6 contrat FNSO

${ }^{2}$ Univ. Bordeaux, CNRS, MC

${ }^{3}$ CNRS - Univ Bordeaux

Presenting Author: alain.queffelec@u-bordeaux.fr

The number of scientific articles has increased dramatically and should continue to grow in the coming years. However, the current system, managed by a few for-profit publishers, has become very costly for our institutions. The deposit of preprints in open archives is a solution for rapid dissemination, but the quality of these preprints must be guaranteed. The dissemination of science is evolving rapidly with the widespread use of social networks. The traditional model of publishing in paid journals is increasingly being criticized. Calls for the re-appropriation of the system by researchers have multiplied in recent years.

This is why Peer Community In (PCI) was created: to enable communities of researchers to assess the quality of the work deposited in open archives and thus ensure broad dissemination of high-quality science. PCI thus offers an innovative way to communicate our scientific results: free for authors and readers, open, online and peer-reviewed. PCI also supports Open Science and scientific reproducibility by making mandatory the deposit of all necessary datasets prior to the recommendation of any preprint and by providing the possibility of pre-registration papers.

Since 2020, a PCI dedicated to Archaeology and gathering more than 80 archaeologists, from all continents, covering all fields of archaeology, was launched. They can handle the submitted preprints as associate editors, but in a more shared and specialized way than a traditional journal would. They can therefore find the best reviewers to assess the quality of the manuscripts!

We managed to do it in Archaeology, why not the Geochemistry community? 